\title{
MARGINAL ADAPTATION AND SEALING ABILITY EVALUATION OF NEW NANO MATERIALS AS ROOT END FILLING MATERIAL (AN INVITRO STUDY)
}

\author{
Hajer M. Abd Elhamid* and Mohamed S. Abdel-Aziz**
}

\begin{abstract}
The aim of this study is evaluating marginal adaptation and sealing ability of nanoMTA and nanohydroxyapatite using bacterial microleakage method for sealing ability and scanning electron microscope (SEM) for marginal adaptation.

Methods: One hundred mandibular premolar extracted teeth were used in this study then divided into two subgroups fifty teeth in each according to root-end filling materials used then further subdivided into twenty-five teeth in each according to the method of assessment. Teeth were prepared using M3 Pro Gold rotary files and obturated with single cone gutta-percha and resin sealer. The apical $3 \mathrm{~mm}$ of the roots were resected. Root-end cavity preparation were prepared and filled with nanoMTA and Nanohydroxyapatite. Group 1: bacterial microleakage assessed to NanoMTA and nanohydroxyapatite by using a model for assessment of bacterial leakage by broth changed color from red (alkaline) to yellow (acidic) as a result of acid production from bacterial growth. The samples were monitored every 24 hours for a period of 30 days. Group2: Marginal gaps between root end filling materials NanoMTA and nanohydroxyapatite with root dentin walls observed under SEM. Data were collected and statically analyzed using ANOVA tests.
\end{abstract}

Results: Samples shows insignificant statistical difference between the two materials in microleakage. However, statistically significant difference at marginal gaps in nano MTA samples and nanohydroxyapatite with better results with nano MTA retrograde filling material.

Conclusion: Nanohydroxyapatite might be a promising mixture to be used as a root-end filling material, as it has about the same bacterial leakage results as nanoMTA

KEYWORDS: NanoMTA, Nanohydroxyapatite, Microleakage, Marginal Gap, Sealing ability, E Faecalis, SEM

\footnotetext{
* Lecturer of Endodontics, Endodontic Department, MTI University.

** Professor of Microbial Chemistry, Microbial Chemistry Department, National Research Center, Giza.
} 


\section{INTRODUCTION}

One of our obligation to our profession is to always search for new materials and/or techniques that would improve the quality and success of our endodontic treatment. An ideal root end filling material should be biocompatible, insoluble in tissue fluids, dimensionally stable, radiopaque, bio inductive and the most important is its ability to prevent microleakage and establish an effective apical seal.

Mineral trioxide aggregate (MTA) has been considered an excellent root canal filling material has excellent sealing ability, biocompatible and provide an appropriate healing response due to its bioactive property and its ability to promote a biomineralization process. ${ }^{[1,2]}$ Nanotechnology has enabled the production of nanoscale dental materials with improved physicochemical properties. Introducing of nano MTA enhances the physical properties of the material to gain the maximum clinical and biological benefits.

Hydroxyapatite has been used in various dental material and procedures as root canal sealers, reto filling material to enhance the mechanical, physicochemical and biological properties of materials. Nanohydroxyapatite (nHA) is considered a biocompatible and bioactive material, and has a great role in supporting bone growth and has osteoconductive property. Dasgupta, et al. ${ }^{[3]}$ evaluated the properties presented by micro and nanoparticles of hydroxyapatite (nHA), and observed better physical, mechanical and biological properties for the material with particle sizes of $168 \mathrm{~nm}$. Nanohydroxyapatite, due to its particle size which is close to the apatite crystals present naturally in teeth mineralised tissue which is useful when used as a scaffold material in tissue engineering ${ }^{[4]}$. It also presents superior properties regarding enhancing stem cells proliferation and differentiation into osteoblasts resulting in bone formation ${ }^{[5]}$. Moreover, nano hydroxyapatite plays a remarkable role in guided tissue regeneration to enhance bone regeneration in the field of periodontology ${ }^{[6]}$.

Most endodontic failures occur as a result of leakage of microorganism and their by-products from pathologically involved filled root canal system and destroy periradicular tissue. Numerous investigators have examined leakage properties of different retrofill materials using a variety of techniques. ${ }^{[7]}$

Several properties of different materials, such as marginal adaptation and biocompatibility, have been evaluated in several studies. Scanning electron microscopy (SEM) at high magnifications has been used to analyze the interface between dentin and root-end filling material and to evaluate marginal adaptation ${ }^{[8]}$

\section{MATERIALS AND METHODS:}

One hundred mandibular single rooted extracted premolar with single canal were selected to the present study and stored in normal saline. Digital radiographs with RVG were taken to confirm canal anatomy in a mesiodistal and buccolingual plane. Crowns were sectioned at the level of cementoenamel junction CEJ with fissure stone in a water-cooled, high-speed handpiece and the length of the roots was adjusted to approximately $16 \mathrm{~mm} .{ }^{[9]}$ The root sections were instrumented up to a master apical size of \#45 taper 0.04 using M3 Pro Gold nickel-titanium rotary files. The canals were irrigated with $5.25 \% \mathrm{NaOCl}$ during instrumentation. All root canals were obturated by single cone guttapercha technique and resin sealer. The apical $3 \mathrm{~mm}$ was resected from the roots at 90 degrees to the long axis of the root canal using a fissure stone and a high-speed with water. A 3-mm deep, root-end preparation was made using an Acteon Neosonic P5 ultrasonic unit using retrograde cavity tip AS3D with the long axis of the root canals.

For Group1: Fifty of the prepared root sections were divided into four groups were tested for bacterial microleakage. Five apparatuses with the 
root canals acted as positive controls were coated by 2 layers of nail polish except for the area of the root tip and constructed with only obturation and no retrofill for maximum leakage. Five apparatuses acted as negative controls the root tip were also coated with nail polish and were constructed with sticky wax at the apical end for no leakage. [9] Forty prepared roots were subdivided into twenty prepared root canals in each subgroup was filled with one of the retrofill materials: Nano MTA and (nHA) nanohydroxyapatite. The retropreparations were disinfected in $5.25 \% \mathrm{NaOCl}$ for 60 s then air dried with a water air syringe. Each of the materials nanoMTA and nanohydroxyapatite were mixed with saline into a thick, creamy consistency and condensed against a premeasured gutta-percha cone fitted $3 \mathrm{~mm}$ from the apex. After the retrofills were condensed, the apices of all experimental root sections were placed onto a sponge and stored at $37^{\circ} \mathrm{C}$ for $48 \mathrm{~h}$.

The model used for bacterial leakage in this study was modified from a technique described by Gish [10]. The apical $4 \mathrm{~mm}$ of each sample protruded into a cut segment of a Eppendorf tube. The junctions were secured with sticky wax to confirm the sealing and prevent microleakage.. Two coats of nail varnish were applied to the middle and coronal thirds of the teeth. Each root canal was aseptically inoculated with $10 \mathrm{ml}$ of freshly prepared E. fecalis culture (100 cells/ ml, ATCC29212). To ensure the viability of the micro organism throughout the experiment, the contents of each root canal were washed out with sterile water twice per week and re-inoculated with fresh $10 \mathrm{ml}$ E. fecalis. The root-ends were completely immersed in Brain Heart Infusion (BHI) broth containing 1 drop of $0.04 \%$ phenol red indicator solution and incubated at $37^{\circ} \mathrm{C}$ in a 5\% CO2 atmosphere. Assessment of the bacterial leakage was made when the broth changed color from red (alkaline) to yellow (acidic) as a result of acid production from bacterial growth. The samples were monitored every $24 \mathrm{~h}$ for a period of 30 days. In the event of a color change, $5 \mathrm{ml}$ of the yellow culture broth were removed, streaked onto BHI agar plates, and allowed to grow for 3 days at $37^{\circ} \mathrm{C}$ in a $5 \% \mathrm{CO}_{2}$ atmosphere. That were performed to confirm that the recovered bacteria were E. fecalis. [9]

For Group2: Fifty of the prepared root canals sections were divided into 2 groups were tested for marginal adaptation twenty-five prepared root canal in each filled with one of the retrofill materials: nanoMTA and (nHA) nanohydroxyapatite.

The apical portion of the roots was then sectioned to obtain two $1 \mathrm{~mm}$ thick transversal sections then mounted on an aluminum stub. Then sputter coating with gold were done. The samples were viewed under a (SEM)scanning electron microscope [National Research Center (QUANTA FEG250)] under magnification 200X and the distance between the root end filling material and the retro cavity dentine walls were measured at two selected points at the material-dentine interface. The photomicrographs at 200x magnification were analyzed on the software Image Tool 3.0 and the extent of gap was measured linearly, in micrometers. The average between the 2 points was calculated and the mean and SD of sample gaps were calculated. ${ }^{[11]}$ Statistical analysis of the results was performed using the ANOVA one way test at 5\% significance level.

To assess the bacterial leakage the total number the samples were monitored every $24 \mathrm{~h}$ for a period of 4 weeks. Statistical analysis Quantitative data were tabulated and analyzed using Microsoft excel software with real statistics resource pack Add in. The results were analyzed using ANOVA two factor test for significant differences between groups and subgroups. Level of significance was set at P less than or equal to 0.05 .

\section{RESULTS}

In the first group the numbers of samples with bacterial leakage at the end of each week are listed in Table 1. None of the negative controls showed any color change indicating no leakage and all of 
the positive controls demonstrated a color change indicating leakage within the first $24 \mathrm{~h}$. Nano MTA samples demonstrated a color change indicating bacterial leakage ranging from one to three samples per week, resulting in a total of eight root canals of twenty with leakage at the end of the $4^{\text {th }}$ week observation period. However, one sample in the nanoMTA group leaked during the $1^{\text {st }}$ week, two samples leaked during the $2^{\text {nd }}$ and $4^{\text {th }}$ week and 3 samples leaked in the $3^{\text {rd }}$ week. In nHA group 4 samples leaked at the $1^{\text {st }}$ and $4^{\text {th }}$ week, 2 in the $2^{\text {nd }}$ week and 3 in the $3^{\text {rd }}$ week with total of thirteen root canal of twenty with leakage at the end of the $4^{\text {th }}$ week observation period. The percentage of leakage in each group at various time intervals is shown in table 1 . The nano MTA group (8/20) leaked less than the nHA group (13/20). However, this was statistically insignificant. As P value was 0.19 (i.e.: more than alpha value which is 0.05 ) between the two materials. At each material through time leakage difference also was not significant with $\mathrm{p}$ value 0.7 (i.e.: more than alpha value which is 0.05 ). the samples mean that leaked in the nano MTA is 10 percent and in the nHA is 16 percent.

Bacteria recovered from the culture broth showing color change was confirmed via light microscopy at $15 \mathrm{x}$ after Gram staining. Gram + cocci in chains were observed consistent with the morphology of E faecalis

In the second group of samples the scanning electron microscope SEM micrographs of root canals with tested retrograde filling materials showed multiple marginal gap at dentin-filling interface. In nanoMTA group, the mean gaps between root-end filling and dentin $0.96+/-0.54 \mathrm{~mm}$, but nHA groups had $2.36+/-0.8 \mathrm{~mm}$. (Figure 1). Table 2 shows the mean \pm SD of gaps found in each group. Based on ANOVA one-way test, there was significant difference in marginal adaptation between the 2 experimenal groups $\mathrm{p}$ value is $4.16 \times 10^{-9}$ which is far less than alpha value 0.05 .

TABLE (1) Samples of the two retrograde materials and the control groups that leaks during time interval

\begin{tabular}{|c|c|c|c|c|c|c|}
\hline & WEEK 1 & WEEK 2 & WEEK 3 & WEEK 4 & Total & Mean percentage /SD \\
\hline Nano MTA & $1 / 20$ & $2 / 20$ & $3 / 20$ & $2 / 20$ & $8 / 20$ & \\
\hline Percentage & $5 \%$ & $10 \%$ & $15 \%$ & $10 \%$ & $40 \%$ & $10+/-4.082$ \\
\hline nHA & $4 / 20$ & $2 / 20$ & $3 / 20$ & $4 / 20$ & $13 / 20$ & \\
\hline Percentage & $20 \%$ & $10 \%$ & $15 \%$ & $20 \%$ & $64 \%$ & $16+/-4.787$ \\
\hline Positive control & $20 / 20$ & $20 / 20$ & $20 / 20$ & $20 / 20$ & $20 / 20$ & \\
\hline Percentage & $100 \%$ & $100 \%$ & $100 \%$ & $100 \%$ & $100 \%$ & ---- \\
\hline Negative control & $0 / 20$ & $0 / 20$ & $0 / 20$ & $0 / 20$ & $0 / 20$ & \\
\hline Percentage & $0 \%$ & $0 \%$ & $0 \%$ & $0 \%$ & $0 \%$ & ---- \\
\hline
\end{tabular}

TABLE (2):

\begin{tabular}{|l|c|c|c|}
\hline Root end filling material & Mean + - SD & Minimum $(\mu \mathrm{m})$ & Maximum $(\mu \mathrm{m})$ \\
\hline nanoMTA & $0.96+/-0.54$ & 0.1 & $1.9(\mu \mathrm{m})$ \\
\hline nHA & $2.36+/-0.80$ & 1.3 & $3.7(\mu \mathrm{m})$ \\
\hline
\end{tabular}



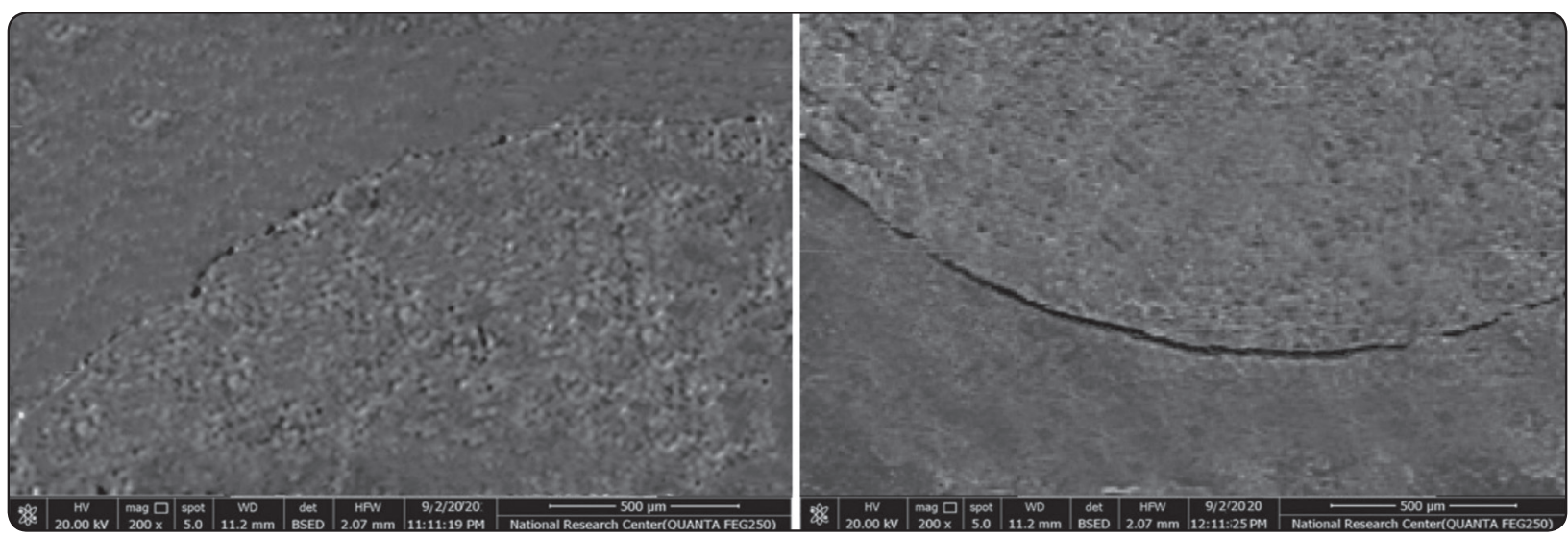

Fig. (1) Scanning electron micrograph showing marginal adaptation of root end filling material a: nanoMTA b: nHA under magnification of $200 \mathrm{X}$

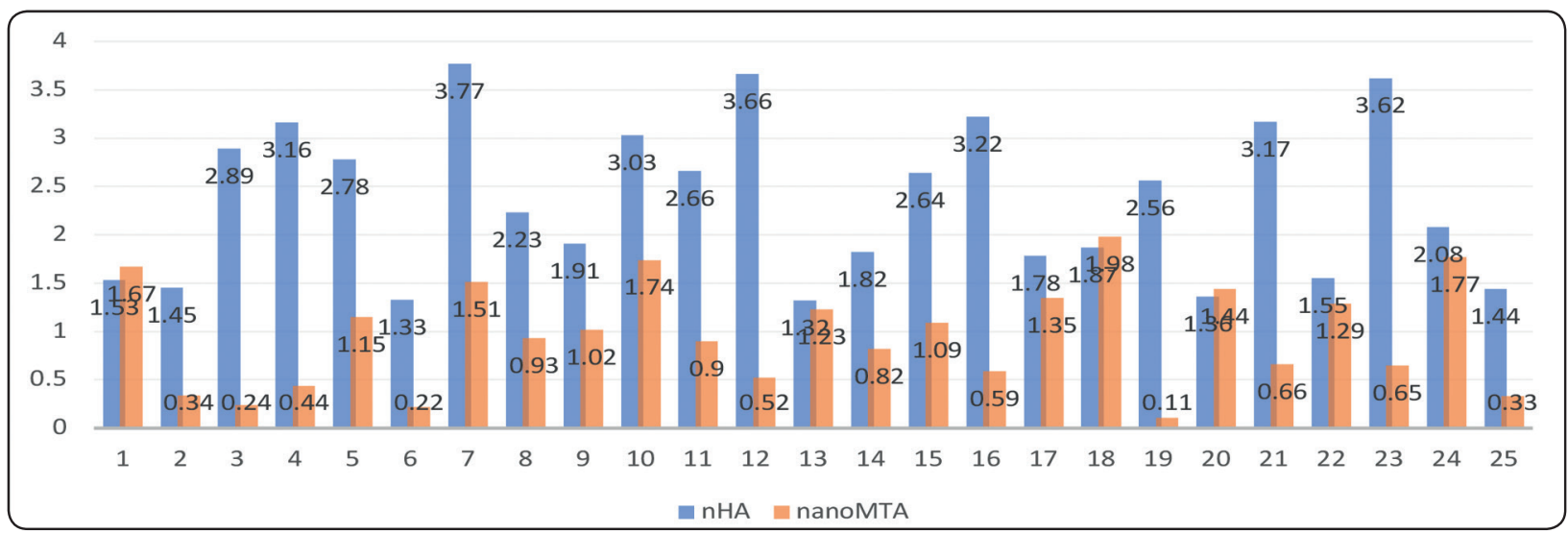

Chart 1: Showing the gap distance in micrometers between the root end filling material and the dentine wall of the root canal using different materials (nanoMTA, nHA)

\section{DISCUSSION}

Apicectomies with root end resection and then placement of retrograde filling material has been recommended in case of failure of non-surgical retreatment trails ${ }^{[12,13]}$

Apical root resection was made by removing $3 \mathrm{~mm}$ of each apex as this would eliminate $98 \%$ of apical ramifications and $93 \%$ of lateral canals which may contribute to periapical pathosis ${ }^{[14]}$. Retrograde cavities were prepared with ultrasonic tips because they produce cleaner, well-centered and more conservative 90 degree root end cavities than those made by conventional burs since beveling would increase permeability due to increase in opening dentinal tubules that communicate with the root canal ${ }^{[15]}$ but studies reveals that there were no significate differences on sealing ability and microleakage between the beveling and conventional technique but it depends on the retrograde material itself ${ }^{[16]}$

The purpose of placing a retrograde sealing after apicectomy is to establish an effective barrier between the root canal filling material and periapical tissue. [17] The ideal root-end filling material provides an adequate seal, should be biocompatible easy to manipulate, dimensionally stable, and not affected by moisture contamination present in the surgical environment ${ }^{[18]}$. Among the available root-end filling materials, MTA has been found to be biocompatible, has excellent sealing ability 
and marginal adaptation in addition to resisting microleakage ${ }^{[19-21]}$ and able to promote hard tissue formation ${ }^{[22-24]}$.

In this in vitro study was to compare the bacterial microleakage and marginal adaptation of the nano particles of one commonly used materials MTA with a new nanohydroxyapatite as a root end filling material.

Using nano hydroxyapatite, due to its particle size that is close to the apatite crystals present naturally in human mineralised tissue ${ }^{[25]}$ also found to be useful when used as a scaffold material in tissue engineering ${ }^{[26,27]}$. It also presents superior properties regarding enhancing stem cells proliferation and differentiation into osteoblasts resulting in bone formation ${ }^{[28]}$. Moreover, nano hydroxyapatite plays a remarkable role in guided tissue regeneration to enhance bone regeneration in the field of periodontology ${ }^{[29]}$. Therefore, using it as retrograde filling material and evaluate it microleakage and marginal adaptation was relevant.

Many leakage models have been developed to study the sealing of root-end filling materials. The bacterial model system used in this study was chosen because it is more clinically relevant. The bacterial species used was E. Faecalis that is a facultative anaerobic bacterium found to be predominant in endodontically treated cases failure and is present in large quantities in dentinal tubules and periapical tissues ${ }^{[30]}$. Because of the fermentation of carbohydrates, this microorganism produced rapid acid production that lowered the $\mathrm{pH}$ causing the phenol red to turn from red to yellow ${ }^{[31]}$. This color change signified microleakage and was visually detectable in the growth media. Several studies investigated E. Faecalis microleakage with different retrograde filling with different methods ${ }^{[32]}$

In summary, by using an in vitro bacterial leakage model, it was found that there was no statistically significant differences between the two materials, also in the same material during time interval even though nanoMTA insignificantly superior to (nHA) as a root-end filling material in resisting bacterial leakage. In comparison nanoMTA with nHA in marginal adaptation using SEM nano MTA was superior that nHA with statistically significant differences between the two retrograde materials. Further studies are indicated to examine other properties of nHA as a root-end filling material such as animal usage models, and long-term sealing and stability studies.

\section{CONCLUSION}

In conclusion, our results indicates that there was varying degree of gap formation noted at dentin filling interface in all the samples with significantly higher gap size in nHA compared to nano MTA nano MTA showed least gap size when compared to nHA suggesting a better marginal adaptation. Also, there were better results with bacterial leakage in nano MTA than nHA with insignificant differences between both retrograde materials. That means those gaps were not enough for bacterial leakage thus it was statistically significant but clinically insignificant. However, further long term clinical studies may be required to find the best root-end filling material.

\section{REFERANCES}

1- William Philip Saunders, A prospective clinical study of periradicular surgery using Mineral trioxide aggregate as a root-end filling, Journal of Endodontology, 34(6), 2008, 660-664

2- Torabinejad M, Parirokh M. Mineral trioxide aggregate: a comprehensive literature review-part II: leakage and biocompatibility investigations. J Endod. 2010 Feb;36(2):190202

3- Dasgupta S, Tarafder S, Bandyopadhyay A, Bose S. Effect of grain size on mechanical, surface and biological properties of microwave sintered hydroxyapatite. Mater Sci Eng C Mater Biol Appl. 2013;33:2846-54. 
4- He H, Yu J, Cao J, E L, Wang D, Zhang H, et al. Biocompatibility and osteogenic capacity of periodontal ligament stem cells on nHAC/PLA and HA/TCP scaffolds. J Biomater Sci Polym Ed. 2011;22(1-3):179-94.

5- Lee JK, Hwang KH. Particle size effects on the bone formation of hydroxyapatite/stem cell biocomposites. Journal of Ceramic Processing Research. 2012;13(2):158-63.

6- Vitti RP, Prati C, Silva EJNL, Sinhoreti MAC, Zanchi CH, De Souza E, Silva MG, et al. Physical properties of MTA fillapex sealer. J Endod. 2013;39(7):915-8.

7- Mangin C, Yesilsoy C, Nissan R, Stevens R. The comparative sealing ability of hydroxyapatite cement, mineral trioxide aggregat, and super ethoxybenzoic acid as root-end filling materials. J Endod. 2003 Apr;29(4):261-4.

8- Costa AT, Konrath F, Dedavid B, Weber JB, de Oliveira MG.Marginal adaptation of root-end filling materials:an in vitro study with teeth and replicas. J Contemp Dent Pract. 2009 Mar 1;10(2):75-82.

9- Maltezos C, Glickman GN, Ezzo P, He J. Comparison of the sealing of Resilon, Pro Root MTA, and Super-EBA as root-end filling materials: a bacterial leakage study. J Endod. 2006 Apr;32(4):324-7.

10- Gish SP, Drake DR, Walton RE, Wilcox L. Coronal leakage: bacterial penetration through obturated canals following post preparation. J Am Dent Assoc 1994;125:1369 -72.

11- Gundam S, Patil J, Venigalla BS, Yadanaparti S, Maddu R, Gurram SR.Comparison of marginal adaptation of mineral trioxide aggregate, glass ionomer cement and intermediate restorative material as root-end filling materials, using scanning electron microscope: An in vitro study.J Conserv Dent. 2014 Nov;17(6):566-70.

12- Song M, Kim HC, Lee W, Kim E.Analysis ofthe cause of failure in nonsurgical endodontic treatment by microscopic inspection during endodontic microsurgery. J Endod. 2011 Nov;37(11):1516-9.

13- Torabinejad M1, Corr R, Handysides R, Shabahang S.Outcomes of nonsurgical retreatment and endodontic surgery: a systematic review. J Endod. 2009 Jul;35(7):9307.

14- Kim S, Kratchman S. Modern endodontic surgery concepts and practice: a review. J Endod 2006; 32:601

15- Khabbaz MG, Kerezoudis NP, Aroni E, Tsatsas V. Evaluation of different methods for the root-end cavity preparation. Oral Surg Oral Med Oral Pathol Oral Radiol
Endod. 2004 Aug;98(2):237-42.

16- Post LK, Lima FG, Xavier CB, Demarco FF, GerhardtOliveira M.Sealing ability of MTA and amalgam in different root-end preparations and resection bevel angles: an in vitro evaluation using marginal dye leakage. Braz Dent J. 2010;21(5):416-9.

17- Bodrumlu E. Biocompatibility of retrograde root filling materials: a review. Aust Endod J. 2008 Apr;34(1):30-5.

18- Gartner AH, Dorn SO. Advances in endodontic surgery. Dent Clin North Am 1992;36:357-78.

19- Torabinejad M, Smith PW, Kettering JD, Pitt Ford TR. Comparative investigation of marginal adaptation of mineral trioxide aggregate and other commonly used rootend filling materials. J Endod 1995;21:295-9.

20- Torabinejad M, Watson TF, Pitt Ford TR (1993). Sealing ability of a mineral trioxide aggregate when used as a root end filling material. J. Endod. 19: 591-595.

21- Fischer E, Arens D, Miller C. Bacterial leakage of MTA as compared with zinc-free amalgam, IRM, and sEBA as a root-end filling material. J Endodon 1998;24:176-9.

22- Torabinejad M, Rastegar AF, Kettering JD, Pitt Ford TR. Bacterial leakage of mineral trioxide aggregate as a rootend filling material. J Endod 1995;21:109 -12.

23- Xavier CB, Weismann R, de Oliveira MG, Demarco FF, Pozza DH.Root-end filling materials: apical microleakage and marginal adaptation. J Endod. 2005 Jul;31(7):539-42.

24- Torabinejad M, Pitt Ford TR, McKendry DJ, Abedi HR, Miller DA, Kariyawasam SP. Histologic assessment of mineral trioxide aggregate as a root-end filling in monkeys. J Endod 1997;23:225- 8. 15.

25- Collares FM, Leitune VC, Rostirolla FV, Trommer RM, Bergmann CP, Samuel SM. Nanostructure hydroxyapatite as filler for methacrylate-based root canal sealers. Int Endod J. 2012;45:63-7.

26- He H, Yu J, Cao J, E L, Wang D, Zhang H, et al. Biocompatibility and osteogenic capacity of periodontal ligament stem cells on nHAC/PLA and HA/TCP scaffolds. J Biomater Sci Polym Ed. 2011;22(1-3):179-94.

27- Venkatesan J, Kim SK. Nano-hydroxyapatite composite biomaterials for bone tissue engineering - a review. J Biomed Nanotechnol. 2014;10:3124-40.

28- Lee JK, Hwang KH. Particle size effects on the bone formation of hydroxyapatite/stem cell biocomposites. 
Journal of Ceramic Processing Research. 2012;13(2):15863.

29- Vitti RP, Prati C, Silva EJNL, Sinhoreti MAC, Zanchi CH, De Souza E, Silva MG, et al. Physical properties of MTA fillapex sealer. J Endod. 2013;39(7):915-8.

30- Rocas IN, Siqueira JF Jr, Santos KR. Association of Enterococcus faecalis with different forms of periradicular diseases. J Endod. 2004 May;30(5):315-20.

31- Adamo HL, Buruiana R, Schertzer L, Boylan RJ. A comparison of MTA, Super-EBA, composite and amalgam as root-end filling materials using a bacterial microleakage model. Int Endod J 1999;32:197-203

32- Nair U, Ghattas S, Saber M, Natera M, Walker C, Pileggi R.A comparative evaluation of the sealing ability of 2 root-end filling materials: an in vitro leakage study using Enterococcus faecalis. Oral Surg Oral Med Oral Pathol Oral Radiol Endod. 2011 Aug;112(2):e74-7. 